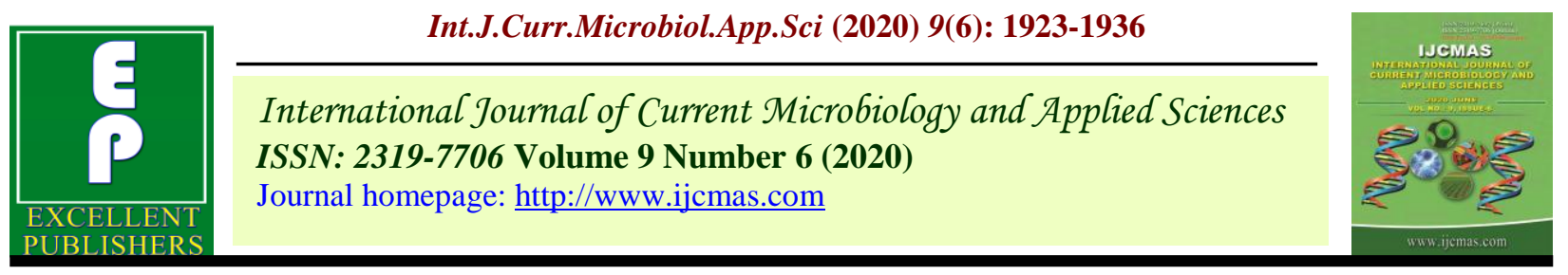

Original Research Article

https://doi.org/10.20546/ijcmas.2020.906.238

\title{
Isolation and Identification of Periplasmic Proteins in Salmonella Typhimurium
}

\author{
Arijit Shome $^{1 *}$, Manoj Kumawat ${ }^{1,3}$, Pavan Kumar Pesingi, ${ }^{2,4}$, \\ Sanjeev Kumar Bhure ${ }^{1}$ and Manish Mahawar ${ }^{1}$ \\ ${ }^{1}$ Division of Biochemistry and ${ }^{2}$ Veterinary Public Health \\ Indian Veterinary Research Institute, Izatnagar, UP 243122 India \\ ${ }^{3}$ ICMR-National Institute for Research in Environmental Health, Bhopal, MP 462030 India \\ ${ }^{4}$ Faculty of Veterinary and Animal Sciences, BHU, Varanasi- India \\ *Corresponding author
}

\begin{tabular}{|l|}
\hline Key w o r d s \\
Salmonella \\
Typhimurium, \\
Periplasmic proteins \\
\hline Article Info \\
$\begin{array}{l}\text { Accepted: } \\
\text { 18 May 2020 } \\
\text { Available Online: } \\
\text { 10 June 2020 }\end{array}$ \\
\hline
\end{tabular}

A B S T R A C T

Between the outer and inner membranes, Gram-negative bacteria contain a narrow space known as periplasm. Periplasm is very tiny spice; however, it is the home for many vital proteins required for various physiological functions as well as bacterial survival under stress conditions. In the current study, we have isolated and identified periplasmic proteins from enteric pathogen Salmonella Typhimurium. Based on the colonization pattern, first, we selected E-5591 as a virulent strain of Salmonella Typhimurium. Next, we isolated periplasmic proteins from E-5591 by modified osmotic shock method. The extraction was monitored by the estimation of malate dehydrogenase (MDH) activity. We have observed more than $90 \% \mathrm{MDH}$ activity $(p<0.001)$ in the cytoplasmic fraction. By LC-MS/MS, we have identified 117 periplasmic proteins and categorized them in 14 functional categories. Finally, we have discussed the role(s) of important proteins in bacterial physiology and virulence, with an emphasis on Salmonella Typhimurium.

\section{Introduction}

Salmonella enterica subspecies enterica serovar Typhimurium ( $S$. Typhimurium), is one of the most notorious known enteric pathogens associated with mild enteritis in healthy individuals. However, it can cause very severe infections in young and immunocompromised individuals. Poultry birds harbor $S$. Typhimurium without showing any symptoms. However, infected birds serve as carriers and are the major source of $S$. Typhimurium infection to humans. Inside the host, $S$. Typhimurium experiences several stresses, including, antimicrobials, starvation, extreme $\mathrm{pH}$ of gastric and intestinal secretions, bile salts, and various oxygen and nitrogen species. 
The periplasm is a tiny viscous compartment localized between outer and inner membranes. The periplasmic space is the home for many important proteins involved in various physiological functions, including osmoregulation, envelope assembly, peptidoglycan synthesis, and envelope stress responses etc (Miller and Salama 2018). On the other hand, it is the first compartment that comes in contact with various stress molecules in the host like $\mathrm{pH}$ extremes, bile salts, oxidants, other immune effectors molecules.

The periplasmic proteins play a very crucial role(s) in combating various stresses thus facilitate the colonization of bacterial pathogens including $S$. Typhimurium in the host. However, a detailed analysis of the expression of various periplasmic proteins in the $S$. Typhimurium is not known. In the present study, we have extracted and identified periplasmic proteins from a virulent strain of $S$. Typhimurium. Then, we classified them according to their functions.

\section{Materials and Methods}

\section{S. Typhimurium strains and their culture}

The $S$. Typhimurium strains were provided by National Salmonella Centre (Veterinary), Division of Bacteriology, ICAR-IVRI, Izatnagar, India. They were grown in Luria Bertani broth or on Hektoen enteric agar.

Selection of virulent strain of $S$. Typhimurium

All animal studies were conducted according to protocols of the Institute Animal Ethical Committee (IAEC), IVRI, Izatnagar India. Newly hatched chicks were obtained from central avian research institute (CARI), Izatnagar, India. Salmonella free status of the chicks was determined as described elsewhere
(Pesingi et al., 2017). One week old Salmonella free chicks (ten in each group) were orally inoculated with various strains (E4231, E-4831, E-5587, E-5591, E-2375) of $S$. Typhimurium. Faecal shedding of $S$. Typhimurium was examined on alternate days up to 21 days. Briefly, cloacal swabs were collected in buffered peptone water and incubated for six hours. Such pre-enriched cultures were then diluted and enriched in Rappaport Vassiliadis R10 media and streaked on HEA plates. The isolated colonies were inoculated in urea broth. Urease negative colonies were tested by PCR using Salmonella specific primers (Pesingi et al., 2017; Sangpuii et al., 2018).

\section{Isolation of periplasmic proteins}

Periplasmic proteins were isolated as described earlier (Hiniker and Bardwell 2004) with minor modifications. Isolated colonies (Pesingi et al., 2017) of S. Typhimurium strain E-5591 were grown at $37{ }^{\circ} \mathrm{C}$ on a shaker incubator. The overnight grown cultures were diluted in fresh media $(1: 100)$ and grown up to mid $\log$ phase $\left(\mathrm{OD}_{600}\right.$ of about 0.80 ). The cultures were then harvested at $3000 \mathrm{x} g$ for 20 minutes at $4^{\circ} \mathrm{C}$. Pellets were suspended in $200 \mu \mathrm{l}$ (for pellet of $20 \mathrm{ml}$ culture) freshly prepared ice-cold Tris Sucrose EDTA (0.2 M Tris-Cl pH-7.4, 4 mM EDTA and $500 \mathrm{mM}$ sucrose) by a sterile wire loop. The suspensions were then incubated for 30 minutes over the ice and periplasmic fraction was collected by centrifugation at $15000 \times g$ for 30 minutes. The remaining pellet was suspended in nuclease free water and lysed by 10 bursts of sonication (each burst of 30 seconds with rest of 30 seconds between bursts). Soluble proteins from such sonicated samples were recovered by centrifugation at $15000 \times \mathrm{g}$ for 10 minutes and labeled as bacterial pellet after extraction of periplasmic proteins. 
Measurement of malate dehydrogenase activity

Malate dehydrogenase (MDH) activity was estimated according to protocol of Sigma (Bergmeyer and Bernt, 1974). Briefly, $933 \mu 1$ of NADH (prepared in potassium phosphate buffer) was aliquoted in a cuvette. To this 33 $\mu \mathrm{l}$ of periplasmic extract or bacterial pellet lysate after extraction of periplasmic proteins was added and mixed with a stirrer.

The reaction was initiated by the adding $33 \mu 1$ substrate (oxaloacetate, from $1 \mathrm{mg} / \mathrm{ml}$ stock). Utilization of NADH was examined by decrease in absorbance at $340 \mathrm{~nm}$ in a Cary 100 Bio UV-visible spectrophotometer. The slope was calculated within 2 minutes after the addition of oxaloacetate. The $\mathrm{MDH}$ activity was calculated as units/ $\mathrm{mg}$ of the protein.

\section{Identification of the periplasmic proteins}

The extraction buffer from the periplasmic proteins changed to $50 \mathrm{mM}$ sodium phosphate buffer ( $\mathrm{pH}$ 7.4) using Slide-A-Lyzer ${ }^{\mathrm{TM}}$ Dialysis Cassettes (Thermo Scientific). The proteins were then concentrated by Vivaspin6 $(3 \mathrm{kDa})$ molecular weight cutoff concentrators (G.E. Healthcare).

Proteins were identified by mass spectrometry by outsourcing at Sandor Life Sciences, Hyderabad, India. Briefly, the samples were incubated with DTT and then alkylated by iodoacetamide. The excess iodoacetamide was quenched by incubation of the samples with DTT. The samples were then supplemented with digestion buffer $(50 \mathrm{mM}$ ammonium bicarbonate plus $0.1 \%$ SDS) and digested with trypsin.

The resulted peptides were cleaned up by ZipTip, dried and reconstituted in $50 \mu 1$ of $0.1 \%$ formic acid. The peptides were separated on
C18 UPLC column (Waters Inc.) using a $0.1 \%$ formic acid in water to $0.1 \%$ formic acid in acetonitrile gradient for 50 minutes with a flow rate of $0.3 \mathrm{ml} / \mathrm{min}$ and subjected to QTOF for MS analysis (Synapt G2 Mass Spectrometer). Raw data were processed by MassLynx 4.1 (WATERS, peptide editor software) to get the complete integrated sequence of the samples.

The MS/MS spectra of individual peptides were matched to the database for amino acid sequences. Proteins were identified on Protein Lynx Global Server (PLGS) v 3.0.2 software (WATERS) by searching against the UniProt database. The localizations of the identified proteins were predicted using pSORTb v.3.0.2. (http://www.psort.org/psortb/).

\section{Miscellaneous}

Total proteins in various samples were determined by Pierce ${ }^{\mathrm{TM}}$ BCA Protein Assay Kit (Thermo Scientific). Statistical analysis was carried out by the student's $t$-test.

\section{Results and Discussion}

Selection of virulent strain of $S$. Typhimurium

Five isolates of $S$. Typhimurium were analyzed for their colonization abilities in poultry birds. The presence of $S$. Typhimurium in the cloacal swabs was determined as described in materials and methods. Among the tested isolates, the strains E-5591 and E-5587 were detected cumulatively more numbers of times, followed by E-4831, E-2375 and E-4231 (Table 1).

Out of E-5591 and E-5587, the former strain was the most frequently detected which indicates that this strain has more colonization abilities than other tested strains. 
Extraction of periplasmic proteins from $S$. Typhimurium

Periplasmic proteins were extracted by osmotic shock method (Hiniker and Bardwell, 2004). We attempted several culture volumes to extraction buffer ratios. However, most clean periplasmic preparation was obtained when pellet from $20 \mathrm{ml}$ culture was incubated with $200 \mu \mathrm{l}$ of extraction buffer. The proteins were analyzed on SDS-gel (figure 1). We observed several bands in periplasmic extract (indicated by arrows) which were either absent or faint in the bacterial pellet after extraction of periplasmic proteins. Malate dehydrogenase activity was used to monitor the extraction process. Representative slopes for $\mathrm{MDH}$ activity estimation in periplasmic and in the pellet after extraction of periplasmic proteins have been depicted in figure $2 \mathrm{~A}$ and $2 \mathrm{~B}$. The $\mathrm{MDH}$ activities (units/ $\mathrm{mg}$ ) were $1.12 \pm 0.13$ and $11.07 \pm 0.39$ in periplasmic fraction and bacterial pellet after isolation of periplasmic proteins respectively. The majority (more than $90 \%(p<0.001)$ of $\mathrm{MDH}$ activity was present in the bacterial pellet (figure 2C).

Identification of periplasmic proteins in $S$. Typhimurium

By employing LC-MS/MS we have identified 121 proteins that expressed in the periplasm of a virulent strain of $S$. Typhimurium. Identified periplasmic proteins have been classified under various groups according to their functions (Table 2). We provide a comprehensive review of many of the important periplasmic proteins identified in this study. Next, we attempted to highlight the contribution of some of the important proteins in bacterial virulence with special reference to $S$. Typhimurium.

Many identified proteins in our study are known to be involved in protein repair in bacterial pathogens. Periplasmic methionine sulfoxide reductase (MsrP) repairs oxidized methionine (Met-SO) residues in periplasmic proteins. A recent study demonstrated the importance of MsrP in the survival of E. coli against $\mathrm{HOCl}$ (Gennaris et al., 2015) and $C$. jejuni under nitrosative stress (Hitchcock et al., 2010). Peptidyl proline cis-trans isomerase (PPIase) catalyzes isomerisation of the cis- and trans- forms of the proline residues. E. coli has four PPIases that are, $f k p A$, surA, ppiA, and ppiD. Survival protein A (SurA) is a chaperone which helps in correct folding and assembly of outer membrane proteins. SurA recognizes precise patterns and orientations of the aromatic residues in side chains of the outer membrane proteins. $f k p A$ and surA genes are required for Salmonella survival during long term carbon starvation and post stress recovery following exposure to high temperature, acidic $\mathrm{pH}$ and antimicrobial agents (Kenyon et al., 2010). Deletion mutant strains of Salmonella in $f k p A$ and surA genes were found to be defective in survival in epithelial cells and macrophages and showed attenuated virulence in mice (Humphreys et al., 2003; Sydenham et al., 2000; Tamayo et al., 2002). Third class of protein repair enzymes are the thiol disulfide interchange proteins namely DsbA, DsbG, DsbL, DsbC, SrgA and TrbB which are involved in disulfide bond formation in periplasmic proteins. DsbA catalyses disulfide bonds formation in periplasmic proteins. DsbG repairs the single cysteine containing sulfenylated proteins. DsbL is a part of a redox system composed of DsbI and DsbL which mediates the formation of an essential disulfide bond in arylsulfate sulfotransferase (Ezraty et al., 2017).

SrgA, a paralog of DsbA is a thiol-disulfide interchange protein. Its disulfide oxidoreductase activity is required for DsbB function. Interestingly, $\mathrm{SrgA}$ is involved in 
the reoxidation of DsbA. TrbB is a disulfide isomerase, which facilitates proper folding of many proteins encoded by F-plasmid. Several of these disulfide interchange proteins are known to play important roles in Salmonella survival in the host (Schmitt et al., 1994; Peek and Taylor 1992), for example, $d s b A$ and $\operatorname{srg} A$ mutant strains of Salmonella enterica showed reduced virulence in mice (Miki, Okada, and Danbara 2004).

Several proteins involved in cell division are found to be localized in the periplasmic space. They play very important roles in cell division. AmiB hydrolyzes the bond between $\mathrm{N}$-acetylmuramoyl and L-amino acids of peptidoglycan. $a m i B$ knockout mutant strain of Vibrio anguillarum showed increased permeability to organic acids like lactate and acetate and hyper-susceptibility to in vitro oxidants such as $\mathrm{H}_{2} \mathrm{O}_{2}$ (Ahn et al., 2006). FtsP (SufI) is a cell division protein that is involved in protecting and stabilizing the divisional assembly under the stress conditions. Deletion mutant strain of E. coli in sufI gene was found to be hypersensitive to superoxide, elevated temperature, low osmotic-strength media and exhibited cell filamentation and DNA damage (Samaluru, Saisree, and Reddy 2007). TolB is a part of the Tol-Pal system which binds and sequesters Pal from murein. TolA later displaces Pal from TolB and allows Pal to bind to septal murein, which causes the outer membrane to invaginate. In $S$. Typhimurium, tolB mutant showed attenuated virulence in mice (Bowe et al., 1998).

Few proteins involved in cell wall biogenesis were identified in the current study. These proteins have been classified into two functional categories, peptidoglycan recycling and cell wall proteins. $\mathrm{BglX}$ is a periplasmic $\beta$-D-glucoside glucohydrolase which hydrolyses terminal non-reducing $\beta$-Dglucosyl residues from sugars such as cellobiose, arbutin or salicin. Thus it plays an important role in peptidoglycan recycling by cleaving the terminal $\beta$-1, 4-linked $\mathrm{N}$ acetylglucosamine (GlcNAc) from peptidelinked peptidoglycan fragments, giving rise to free GlcNAc. YcbB protein is involved in the pathway of peptidoglycan biosynthesis. $y c b B$ mutant in S. enterica exhibited decreased 3-3 cross-links in peptidoglycan and showed decreased resistance to sodium deoxycholate. ErfK is one among the three genes (other two are YcfS, and YbiS) that code for L, Dtranspeptidases that anchor the Braun lipoprotein (murein lipoprotein) to the peptidoglycan layer. $\mathrm{YbgF} / \mathrm{CpoB}$ is a periplasmic protein that binds to TolA. CpoB mediates coordination of peptidoglycan synthesis and outer membrane constriction during cell division. $c p o B$ mutant of Salmonella showed attenuated phenotype (Masilamani et al., 2018).

Few of the identified proteins have been shown to be involved in stress survival. Superoxide dismutases (SODs) degrade superoxide anion $\left(\mathrm{O}_{2}{ }^{-}\right)$to $\mathrm{H}_{2} \mathrm{O}_{2}$. They play a very important role in bacterial survival against metabolic and host generated superoxides. Indirectly, SODs inhibit the production of highly toxic peroxynitrite by limiting the availability of $\mathrm{O}_{2}^{-}$(a substrate for peroxynitrite production). Depending upon cofactor requirements, four isoforms of SODs have been described, $\mathrm{Cu} / \mathrm{Zn}-\mathrm{SOD}, \mathrm{Mn}-\mathrm{SOD}$, Fe-SOD and Ni-SOD. Owing to periplasmic localization $\mathrm{Cu} / \mathrm{Zn}$ SOD play a very important role in combating phagocyte generated oxidants. $S$. Typhimurium encodes two periplasmic $\mathrm{Cu} / \mathrm{Zn}-\mathrm{SODs}$ (SodCI and SodCII) (Ammendola et al., 2008; Hébrard et al., 2009). Both SodCI and SodCII are found to be important for oxidative stress survival and virulence of various serovars of Salmonella (Fang et al., 1999; Uzzau, Bossi, and Figueroa-bossi 2002; Krishnakumar et al., 2004; Figueroa-Bossi, Ammendola, and Bossi 
2006; Ammendola et al., 2008). A separate study demonstrated hypersensitivity of sodCIsodCII double mutant to activated THP-1 cells (Sly, Guiney, and Reiner 2002).

YdeI is involved in the cellular response to hydrogen peroxide stress. An E. coli ydeI gene deletion mutant showed hypersensitivity to hydrogen peroxide (Lee et al., 2010). A separate study suggested that $S$. Typhimurium ydeI is important for persistent infection in mice as $\Delta y d e I$ mutant strain showed defective colonization in mice (Erickson and Detweiler, 2006).

Gamma glutamyltranspeptidase (GGT) catalyses transfer of $\gamma$-glutamyl moiety from glutathione to amino acids or peptides. GGT plays very crucial role in glutathione degradation in the $\gamma$-glutamyl cycle. GGT maintains the cellular glutathione levels and thus protects the bacterial proteins from host generated oxidants. GGT has been shown to aid gastric colonization of $H$. pylori (Chevalier et al., 1999; Govern et al., 2001).

YggE interacts with the cell membrane and maintains the cellular rigidity. The function of YggE in $S$. Typhimurium virulence is unknown. However, $y g g E$ has been described as a putative SPI-2 gene suggesting its role in the pathogenesis and virulence of $S$. Typhimurium. Further, $y g g E$ is found to be upregulated in response to UV-radiation, thermal stresses and swarming motility (Wang et al., 2004). Omp28 is an acid stress chaperone required for protection against acid stress which is important for the survival of Salmonella in the stomach. At low pH it possesses chaperone-like activity and prevents the aggregation of various periplasmic proteins (Neves-Ferreira et al., 2004). TorA is a part of the trimethylamine N-oxide (TMAO) reductase system which comprises of TorC and TorD apart from TorA. TorA is the terminal reductase which receives the electrons from TorC. Cpx is a two-component envelope stress response system that activates the expression of factors involved in protein folding and degradation. It is comprised of CpxA (histidine kinase) and a response regulator CpxR. This two component system plays a crucial role in the biogenesis of virulence factors as well as protection of several proteins from various stresses. The periplasmic protein, CpxP (identified in our screen) is a small, Cpxregulated protein blocks the activation of the pathway by repressing the regulon.

Few proteins involved in flagellar synthesis are homed in periplasmic space. FlgI protein forms the L-ring and most likely protects the motor/basal body from shearing forces during rotation.

$\mathrm{Flg} \mathrm{A}$ is involved in the assembly process during P-ring formation. FlgA helps in polymerization of $\mathrm{FlgI}$ into the $\mathrm{P}$ ring through FlgA-FlgI interaction.

FlgJ is a flagellum-specific muramidase which hydrolyzes the peptidoglycan layer to assemble the rod structure in the periplasmic space. A study demonstrated the function of this protein in $S$. Typhimurium and showed that the peptidoglycan hydrolyzing function lies in its C- terminal half (Nambu et al., 1999).

TreA is a periplasmic trehalase which splits trehalose into glucose molecules. At high osmolarity it helps bacterial cells to utilize trehalose. The equilibrium between $\alpha$ - and $\beta$ anomers of $\alpha$-N-acetylneuraminic acid (Neu5Ac) is achieved by Nacetylneuraminate mutarotase (NanM) which converts $\alpha$-anomer to its $\beta$-anomer. This facilitates those bacteria which are sialidasenegative ( $E$ coli and $S$. enterica) to compete for limited amounts of extracellular Neu5Ac, which is likely taken up in the $\beta$-anomer. 
Since, endogenously released sialic acid is an inflammatory indicator in the host, its rapid removal from solution might be advantageous to the bacterium to damp down host responses. The sialic acid removal would be helpful for bacterial pathogens to dampen host responses (Severi et al., 2008).

Few identified proteins have role in osmoregulation. Osmoregulated glucans (OPGs) are a group of oligosaccharides present in the bacterial periplasm. They help in maintaining the osmotic pressure inside the cells. Glucan biosynthesis protein G (MdoG) is required for OPGs synthesis. MdoG is involved in polyglucose elongation, branching of the linear precursor as well as transport through the inner membrane and periplasmic release of the OPGs. YhaM is a cysteine desulfhydrase which participates in cysteine catabolism and detoxification. CyuA is the key anaerobic cysteine catabolizing enzyme present in E. coli and S. enterica (Loddeke et al., 2017). CyuA helps S. enterica in utilizing sulfur containing compounds under anaerobic conditions (Loddeke et al., 2017). Protein YceI is an uncharacterized protein. OsmY participates in bacterial adaptation to hyperosmotic stress. In E. coli, upregulation of $\operatorname{osm} Y$ has been reported in response to a variety of stress conditions. OsmY has been shown to limit shrinkage of the cytoplasm by contracting the phospholipid interfaces surrounding the periplasmic space.

Several chaperones are found to be localized in periplasm. FimC is required for the biogenesis of type 1 fimbriae. It interacts with FimF, $G$ and $H$ via D-mannose containing adhesin proteins. fim $C$ mutant strain of $E$. coli K12 showed defective fimbriae synthesis. In $S$. Typhimurium FimC chaperone activity is required for fimbrial assembly on the cell surface (Zeiner, Dwyer, and Clegg 2012).

Table.1 Assessment of colonization abilities of various strains of $S$. Typhimurium in poultry

\begin{tabular}{|l|c|c|c|c|c|}
\hline Strain & E-4231 & E-4831 & E-5587 & E-5591 & E-2375 \\
\hline Dose (CFU/bird) & $10^{9}$ & $10^{9}$ & $10^{9}$ & $10^{9}$ & $10^{9}$ \\
\hline Day 1 & - & 1 & 3 & 3 & 1 \\
\hline Day 3 & - & 2 & 6 & 3 & 2 \\
\hline Day 5 & - & - & 4 & 6 & - \\
\hline Day 7 & - & 2 & 3 & 1 & - \\
\hline Day 9 & - & 3 & 1 & - & - \\
\hline Day 11 & - & - & 1 & 4 & - \\
\hline Day 13 & 1 & - & 3 & 1 & 2 \\
\hline Day 15 & - & 1 & 2 & 2 & - \\
\hline Day 17 & - & - & 3 & 4 & - \\
\hline Day 19 & - & - & 1 & 3 & - \\
\hline Day 21 & 1 & - & - & 2 & - \\
\hline & $\mathbf{2}$ & $\mathbf{8}$ & $\mathbf{2 7}$ & $\mathbf{2 9}$ & $\mathbf{5}$ \\
\hline
\end{tabular}


Table.2 Categorization of identified periplasmic proteins

\begin{tabular}{|c|c|c|c|c|}
\hline S. No. & $\begin{array}{l}\text { Functional } \\
\text { Category }\end{array}$ & Sub Category & $\begin{array}{l}\text { Sub-Sub } \\
\text { Category }\end{array}$ & Genes involved \\
\hline 1 & Protein Repair & & & $\begin{array}{l}\text { msrP, ppiA, surA, dsbA, dsbG, dsbC, } \\
\text { dsbL, trbB, srgA, }\end{array}$ \\
\hline 2 & $\begin{array}{l}\text { Cell division } \\
\text { proteins }\end{array}$ & & & amiB, sufI (ftsP), tolB \\
\hline \multirow[t]{2}{*}{3} & \multirow[t]{2}{*}{$\begin{array}{l}\text { Cell Wall } \\
\text { Biogenesis }\end{array}$} & $\begin{array}{l}\text { Peptidoglycan } \\
\text { Recycling }\end{array}$ & & bglX, ycbB, erfK, ybgF \\
\hline & & Cell wall proteins & & ycfS, yafK \\
\hline 4 & Stress Survival & $\begin{array}{l}\text { Oxidative Stress } \\
\text { Survival }\end{array}$ & & $\begin{array}{l}\text { sodC, sodC1, ydeI, ggt, yggE, ompP, torA, } \\
\text { cpxP }\end{array}$ \\
\hline 5 & $\begin{array}{l}\text { Flagella Synthesis } \\
\text { Proteins }\end{array}$ & & & fglI, fglA, flgJ \\
\hline 6 & Metabolism & & & $\begin{array}{l}\text { treA, nanM, yhaM, ptrA, cpdB, yceI, } \\
\text { aphA, nrfB, agp, mglB, tbpA, mdoD }\end{array}$ \\
\hline 7 & Osmoregulation & & & mdoG, yhaM (cyuA), yceI, osmY \\
\hline 8 & $\begin{array}{l}\text { Proteins imparting } \\
\text { antibiotic resistance }\end{array}$ & & & fhuD, blaCMY, ybhG \\
\hline \multirow[t]{5}{*}{9} & \multirow[t]{5}{*}{ Chaperones } & $\begin{array}{l}\text { Acid Stress } \\
\text { Chaperone }\end{array}$ & & ompP \\
\hline & & \multirow[t]{4}{*}{ Cell Structure } & $\begin{array}{l}\text { Fimbrial } \\
\text { organization }\end{array}$ & stfD, surA, fimC, sefB \\
\hline & & & Pilus structure & stbB, stbE, stcB, pefD, sefB \\
\hline & & & $\begin{array}{l}\text { Cell Wall } \\
\text { Structure }\end{array}$ & stcB, yctS \\
\hline & & & Outer Membrane & skp \\
\hline 10 & Transporters & & & $\begin{array}{l}\text { potD, proX, rbsB, modA, malE, livJ, } \\
\text { ugpB, gltG, yliB, btuF, dppA, fliY, } \\
\text { dctABC, hisJ, mppA, sbp, lsrB, mglB, } \\
\text { livK, artI, yiaO, thud, cysP, sapA, lolA, } \\
\text { argT, yejA }\end{array}$ \\
\hline 11 & $\begin{array}{l}\text { Electron transfer } \\
\text { proteins }\end{array}$ & & & napG, torA, napB, napA, ttrA \\
\hline 12 & Protein folding & & & stfD, ompP, $\operatorname{degP}$, lpfB, ppiA \\
\hline \multirow[t]{3}{*}{13} & \multirow[t]{3}{*}{ Binding Protein } & Metal Ion Binding & & $\begin{array}{l}\text { cybC, sitA, ushA, silE, nrfB, napB, znuA, } \\
\text { modA, merP }\end{array}$ \\
\hline & & $\begin{array}{l}\text { Peptide Binding } \\
\text { protein }\end{array}$ & & livK, oppA, ugpB, fepB \\
\hline & & Polyamine Binding & & potF \\
\hline 14 & Putative & & & phoC, ybhG, ymdA, malM, yceM \\
\hline
\end{tabular}


Figure.1 SDS-gel analysis of periplasmic proteins in S. Typhimurium. Lanes- PP is periplasmic proteins; pellet is bacterial pellet after extraction of periplasmic proteins and $\mathrm{M}$ is molecular weight marker. Protein bands specifically present or darker in periplasmic fraction are marked by arrows

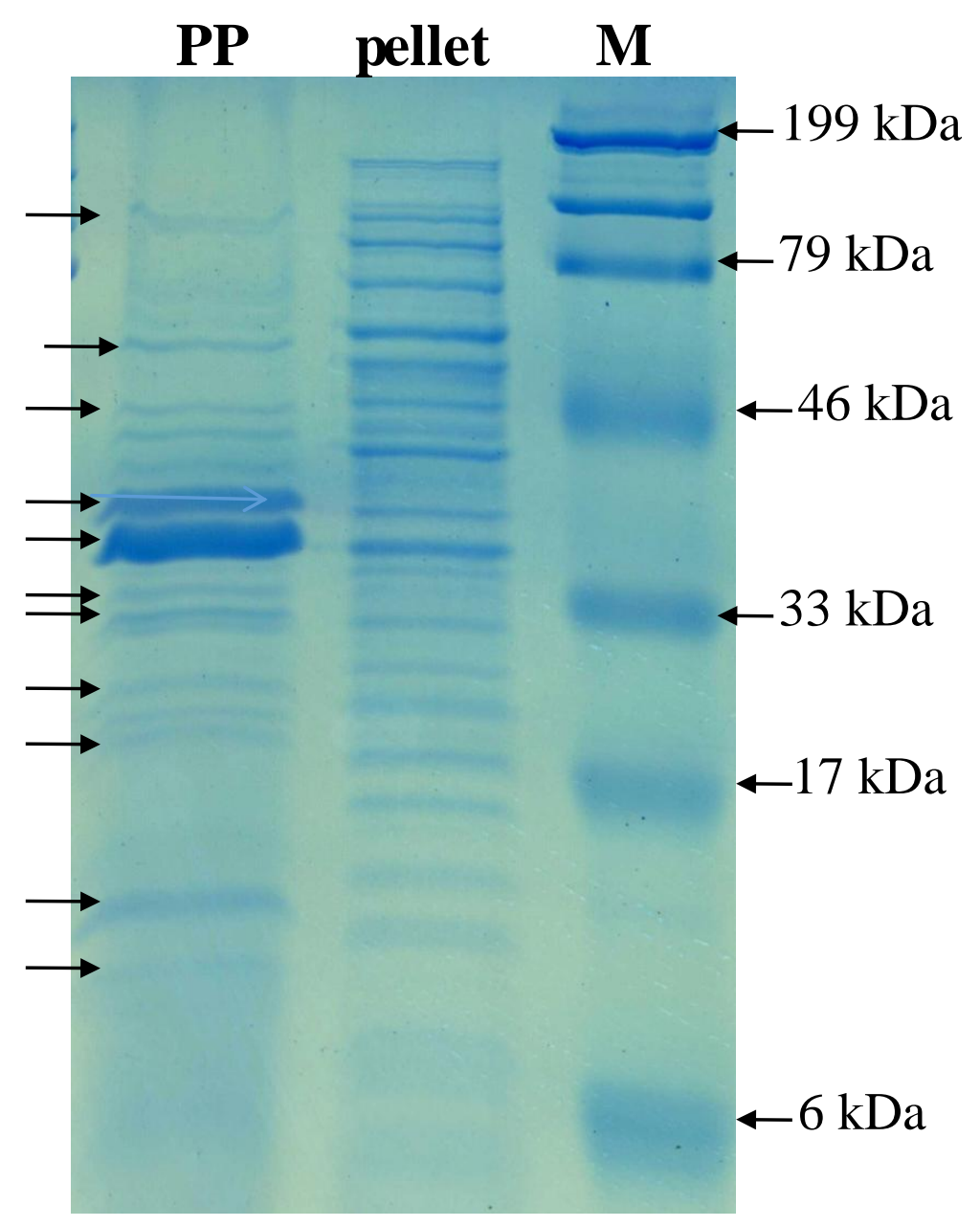


Figure.2 Estimation of malate dehydrogenase activity in periplasmic ( $\mathrm{pp}$ ) fraction (2A) or in the bacterial pellet after extraction of periplasmic proteins (pellet) (2B). Briefly, NADH solution was taken in a cuvette and supplemented with sample. After stabilization of absorbance, oxaloacetate was added and decrease in absorbance of NADH was calculated from slopes. MDH activities

(mean \pm S. D., $n=4$ ) are shown in Fig. 2C

Fig. 2B

Fig. 2A

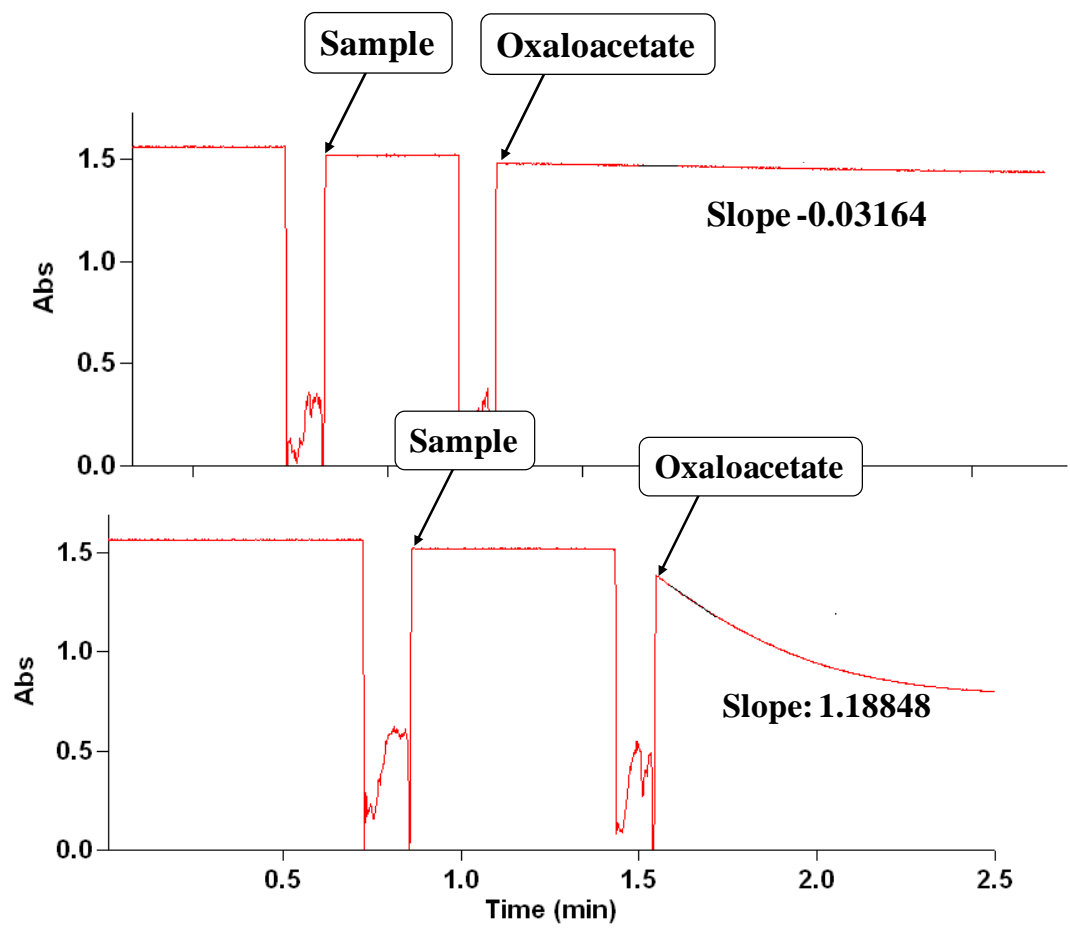

Fig. 2C

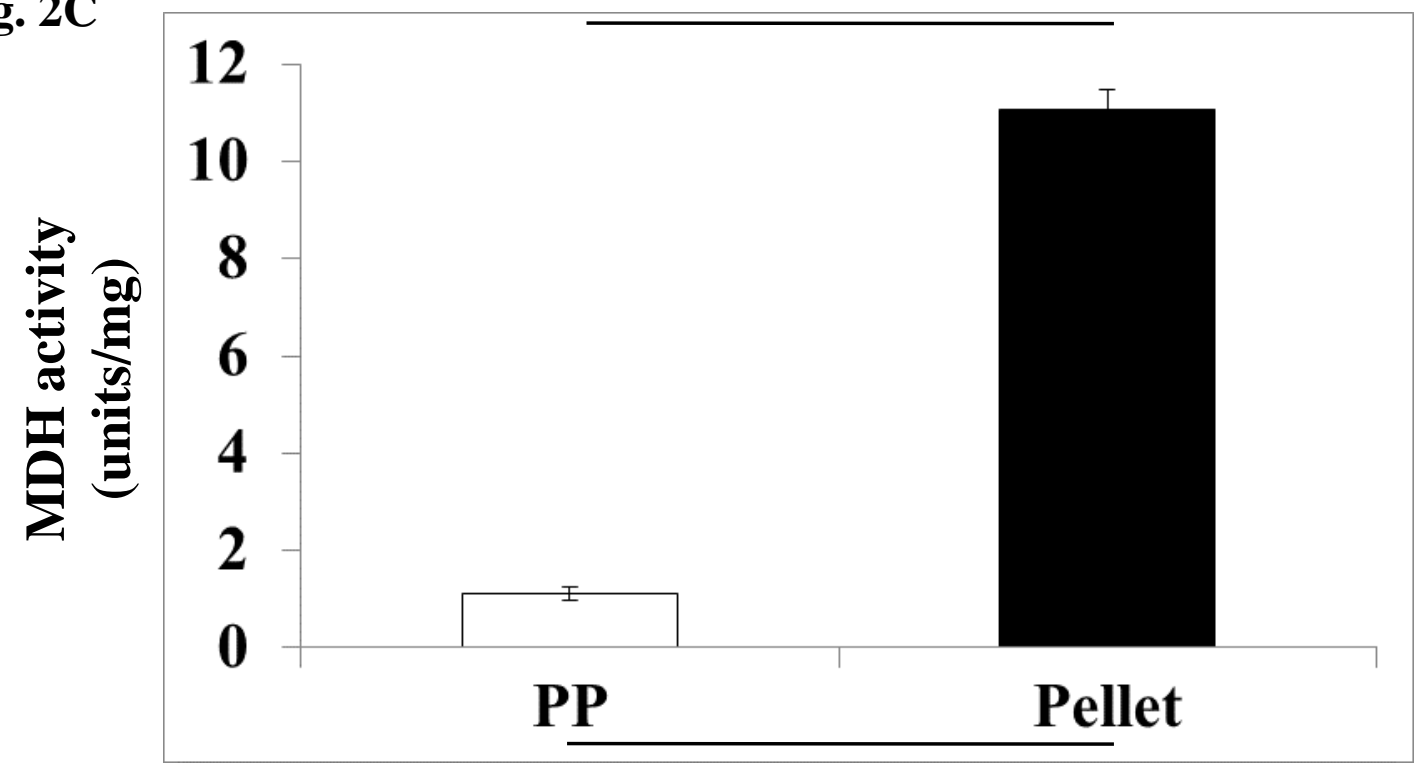

Cellular fraction 
The sef operon is located on a small pathogenicity island of Salmonella. This operon contains four structural genes $(s e f A B C D)$ required for the translocation and biogenesis of SEF14 fimbriae. The major subunit is encoded by sefA. While SefB is a chaperone, sefC encodes for usher activity. sefD encodes the putative adhesion (Edwards, Schifferli, and Maloy 2000). SefB is the chaperone which prevents premature aggregation of the proteins. It is required for the biogenesis of the SefA (SEF14) fimbria.

Several proteins which are part of ATP dependent transporter systems are found to be localized in the periplasmic space. The identified proteins are listed in table 3 . These periplasmic components of the transporter systems mediates transport of various nutrients, peptides, metals and metabolites etc. by binding and facilitating their transfer to inner membrane bound permeases. The permease with help of ATPase activity of other components of transporter, eventually transfer molecules in the cytoplasm. Functions of few such periplasmic proteins have been described below.

FhuD is a periplasmic hydroxamate binding protein which mediates transfer of ferrichydroxamate complex to the membranebound permease. It is essential for the transport of several siderophores, including, ferrichrome, gallichrome, desferrioxamine, coprogen, rhodotorulic acid aerobactin and shizokinen.

PotD binds and facilitates transfer of polyamines like spermidine and putrescine. By working as signaling molecules, polyamines can modulate the virulence of bacterial pathogens, including $S$. Typhimurium (Jelsbak et al., 2012).

Accumulation of antimicrobial peptides in periplasmic space causes disruption of inner membrane and eventually lysis of bacterial cell. SapA is the periplasmic component of SAP transporter system which protects bacterial cells from antimicrobial peptides. SAP system transports antimicrobial peptides into the cytoplasm where peptidases can easily degrade them. sapA gene deletion strain in $S$. Typhimurium showed defective colonization in mice colon. Further, sapA mutant showed hyper-invasion phenotype in epithelial cells (Ondari et al., 2017).

The periplasmic nitrate reductase napA is a part of multi gene operon which is involved in reduction of nitrate to nitrite. A strain of $S$. Typhimurium lacking napA gene exhibited defective colonization in mice colon (Lopez et al., 2015).

In conclusion, periplasmic space of $S$. Typhimurium harbors many proteins. These proteins are required for various physiological processes. Several of the identified proteins are known to be involved in pathogenesis and virulence of this bacterium. Because of their location, periplasmic proteins can be a good target for development of novel therapeutics agents.

\section{Acknowledgements}

This study was funded by a grant (Grant No.: DBT/PR13689/BRB/10/1399/2015) from Department of Biotechnology (DBT), India and NASF, ICAR, India. We thankfully acknowledge the supported provided by the Director, Indian Veterinary Research Institute (IVRI) for the necessary facilities provided.

\section{References}

Ahn, Sun Hee, Dong Gyun Kim, Seung Ha Jeong, Gyeong Eun Hong, and In Soo Kong. 2006. "Isolation of N-Acetylmuramoyl-L-Alanine Amidase Gene (AmiB) from Vibrio Anguillarum and the Effect of AmiB Gene Deletion on Stress Responses." Journal of Microbiology and Biotechnology 16 (9): 
1416-21.

Ammendola, Serena, Paolo Pasquali, Francesca Pacello, Giuseppe Rotilio, Margaret Castor, Stephen J. Libby, Nara Figueroa-Bossi, Lionello Bossi, Ferric C. Fang, and Andrea Battistoni. 2008. "Regulatory and Structural Differences in the $\mathrm{Cu}, \mathrm{Zn}$-Superoxide Dismutases of Salmonella enterica and Their Significance for Virulence." Journal of Biological Chemistry 283 (20): 1368899.

https://doi.org/10.1074/jbc.M710499200.

Bowe, Frances, Craig J. Lipps, Renee M. Tsolis, Eduardo Groisman, Fred Heffron, and Johannes G. Kusters. 1998. "At Least Four Percent of the Salmonella Typhimurium Genome Is Required for Fatal Infection of Mice." Infection and Immunity 66 (7): 3372-77.

Chevalier, Catherine, Jean Michel Thiberge, Richard L. Ferrero, and Agnès Labigne. 1999. "Essential Role of Helicobacter Pylori $\gamma$-Glutamyltranspeptidase for the Colonization of the Gastric Mucosa of Mice." Molecular Microbiology 31 (5): 1359-72. https://doi.org/10.1046/j.13652958.1999.01271.x.

E.M. Ondari. 2017. "Role of SapA and YfgA in Susceptibility." Infection and Immunity 85 (9): 1-15.

Edwards, Robert A., Dieter M. Schifferli, and Stanley R. Maloy. 2000. "A Role for Salmonella Fimbriae in Intraperitoneal Infections." Proceedings of the National Academy of Sciences of the United States of America $97 \quad$ (3): $1258-62$. https://doi.org/10.1073/pnas.97.3.1258.

Ezraty, Benjamin, Alexandra Gennaris, Frédéric Barras, and Jean-françois Collet. 2017. "Oxidative Stress, Protein Damage and Repair in Bacteria." Nature Publishing Group. https://doi.org/10.1038/nrmicro.2017.26.

Fang, Ferric C., Mary Ann Degroote, John W. Foster, Andreas J. Bäumler, Urs Ochsner, Traci Testerman, Shawn Bearson, et al., 1999. "Virulent Salmonella Typhimurium Has Two Periplasmic $\mathrm{Cu}, \mathrm{Zn}$-Superoxide Dismutases." Proceedings of the National Academy of Sciences of the United States of $\begin{array}{lll}\text { America } & 96 & \text { (13): }\end{array}$ https://doi.org/10.1073/pnas.96.13.7502.

Figueroa-Bossi, Nara, Serena Ammendola, and Lionello Bossi. 2006. "Differences in Gene Expression Levels and in Enzymatic Qualities Account for the Uneven Contribution of Superoxide Dismutases SodCI and SodCII to Pathogenicity in Salmonella enterica." Microbes and Infection $8 \quad$ (6): $1569-78$. https://doi.org/10.1016/j.micinf.2006.01.01 5.

Gennaris, Alexandra, Benjamin Ezraty, Camille Henry, Rym Agrebi, Alexandra Vergnes, Emmanuel Oheix, Julia Bos, et al., 2015. "Repairing Oxidized Proteins in the Bacterial." Nature 528 (7582): 409-12. https://doi.org/10.1038/nature15764.

Govern, K J M C, T G Blanchard, J A Gutierrez, and S J Czinn. 2001. " $\square$ Glutamyltransferase Is a Helicobacter Pylori Virulence Factor but Is Not Essential for Colonization" 69 (6): 4168-73. https://doi.org/10.1128/IAI.69.6.4168.

Hébrard, Magali, Julie P.M. Viala, Stéphane Méresse, Frédéric Barras, and Laurent Aussel. 2009. "Redundant Hydrogen Peroxide Scavengers Contribute to Salmonella Virulence and Oxidative Stress Resistance." Journal of Bacteriology 191 (14): 4605-14. https://doi.org/10.1128/JB.00144-09.

Hiniker, Annie, and James C A Bardwell. 2004. "In Vivo Substrate Specificity of Periplasmic Disulfide Oxidoreductases." Journal of Biological Chemistry 279 (13): 12967-73. https://doi.org/10.1074/jbc.M311391200.

Hitchcock, Andrew, Stephen J Hall, Jonathan D Myers, Francis Mulholland, Michael A Jones, David J Kelly, David J Kelly, Western Bank, and S Sheffield. 2010. "Roles of the Twin-Arginine Translocase and Associated Chaperones in the Biogenesis of the Electron Transport Chains of the Human Pathogen Campylobacter Jejuni," 2994-3010. https://doi.org/10.1099/mic.0.042788-0.

Humphreys, Sue, Gary Rowley, Andrew Stevenson, William J. Kenyon, Michael P. Spector, and Mark Roberts. 2003. "Role of Periplasmic Peptidylprolyl Isomerases in 
Salmonella enterica Serovar Typhimurium Virulence." Infection and Immunity 71 (9): 5386-88. https://doi.org/10.1128/IAI.71.9.53865388.2003.

Jelsbak, Lotte, Line Elnif Thomsen, Inke Wallrodt, Peter Ruhdal Jensen, and John Elmerdahl Olsen. 2012. "Polyamines Are Required for Virulence in Salmonella enterica Serovar Typhimurium." PLoS $\begin{array}{llll}\text { ONE } & 7 & (4): & 1-10 .\end{array}$ https://doi.org/10.1371/journal.pone.00361 49.

Kenyon, William J., Sue Humphreys, Mark Roberts, and Michael P. Spector. 2010. "Periplasmic Peptidyl-Prolyl Isomerases SurA and FkpA Play an Important Role in the Starvation-Stress Response (SSR) of Salmonella enterica Serovar Typhimurium." Antonie van Leeuwenhoek, International Journal of General and Molecular Microbiology 98 (1): 51-63. https://doi.org/10.1007/s10482-010-9428-2.

Krishnakumar, Radha, Maureen Craig, James A. Imlay, and James M. Slauch. 2004. "Differences in Enzymatic Properties Allow SodCI but Not SodCII to Contribute to Virulence in Salmonella enterica Serovar Typhimurium Strain 14028." Journal of Bacteriology $186 \quad$ (16): 5230-38. https://doi.org/10.1128/JB.186.16.52305238.2004.

Lee, J., S. R. Hiibel, K. F. Reardon, and T. K. Wood. 2010. "Identification of StressRelated Proteins in Escherichia Coli Using the Pollutant Cis-Dichloroethylene." Journal of Applied Microbiology 108 (6): 2088-2102. https://doi.org/10.1111/j.13652672.2009.04611.x.

Lopez, Christopher A., Fabian Rivera-Chávez, Mariana X. Byndloss, and Andreas J. Bäumler. 2015. "The Periplasmic Nitrate Reductase NapABC Supports Luminal Growth of Salmonella enterica Serovar Typhimurium during Colitis." Infection and Immunity $83 \quad$ (9): 3470-78. https://doi.org/10.1128/IAI.00351-15.

Miki, Tsuyoshi, Nobuhiko Okada, and Hirofumi Danbara. 2004. "Two Periplasmic Bisulfide Oxidoreductases, DsbA and SrgA, Target Outer Membrane Protein SpiA, a
Component of the Salmonella Pathogenicity Island 2 Type III Secretion System." Journal of Biological Chemistry 279 34631-42. https://doi.org/10.1074/jbc.M402760200.

Miller, Samuel I., and Nina R. Salama. 2018. "The Gram-Negative Bacterial Periplasm: Size Matters." PLoS Biology 16 (1): 1-7. https://doi.org/10.1371/journal.pbio.200493 5.

Nambu, Takayuki, Tohru Minamino, Robert M. Macnab, and Kazuhiro Kutsukake. 1999. "Peptidoglycan-Hydrolyzing Activity of the FlgJ Protein, Essential for Flagellar Rod Formation in Salmonella Typhimurium." Journal of Bacteriology 181 (5): 1555-61.

Neves-Ferreira, Ana G.C., Carlos M. De Andrade, Marcos A. Vannier-Santos, Jonas Perales, Hilton J. Nascimento, and José G. Da Silva. 2004. "Complete Amino Acid Sequence and Location of Omp-28, an Important Immunogenic Protein from Salmonella enterica Serovar Typhi." Protein Journal 23 (1): 71-77. https://doi.org/10.1023/B:JOPC.000001626 0.03793.30.

Peek, J. A., and R. K. Taylor. 1992. "Characterization of a Periplasmic Thiol:Disulfide Interchange Protein Required for the Functional Maturation of Secreted Virulence Factors of Vibrio Cholerae." Proceedings of the National Academy of Sciences of the United States of America $\quad 89$ (13): 6210-14. https://doi.org/10.1073/pnas.89.13.6210.

Pesingi, Pavan K., Manoj Kumawat, Pranatee Behera, Sunil K. Dixit, Rajesh K. Agarwal, Tapas K. Goswami, and Manish Mahawar. $2017 . \quad$ "Protein-L-Isoaspartyl Methyltransferase (PIMT) Is Required for Survival of Salmonella Typhimurium at $42^{\circ} \mathrm{C}$ and Contributes to the Virulence in Poultry." Frontiers in Microbiology 8 (MAR): $\quad 1-9$. https://doi.org/10.3389/fmicb.2017.00361.

Samaluru, Harish, L. Saisree, and Manjula Reddy. 2007. "Role of SufI (FtsP) in Cell Division of Escherichia Coli: Evidence for Its Involvement in Stabilizing the Assembly of the Divisome." Journal of Bacteriology 189 (22):

8044-52. 
https://doi.org/10.1128/JB.00773-07.

Sangpuii, Lal, Sunil Kumar Dixit, Manoj Kumawat, Shekhar Apoorva, Mukesh Kumar, Deepthi Kappala, Tapas Kumar Goswami, and Manish Mahawar. 2018. "Comparative Roles of ClpA and $\mathrm{ClpB}$ in the Survival of $S$. Typhimurium under Stress and Virulence in Poultry." Scientific Reports 8 (1): $1-12$. https://doi.org/10.1038/s41598-018-226706.

Schmitt, C. K., S. C. Darnell, V. L. Tesh, B. A.D. Stocker, and A. D. O'Brien. 1994. "Mutation of FlgM Attenuates Virulence of Salmonella Typhimurium, and Mutation of FliA Represses the Attenuated Phenotype." Journal of Bacteriology 176 (2): 368-77. https://doi.org/10.1128/jb.176.2.368377.1994.

Severi, Emmanuele, Axel Müller, Jennifer R. Potts, Andrew Leech, David Williamson, Keith S. Wilson, and Gavin H. Thomas. 2008. "Sialic Acid Mutarotation Is Catalyzed by the Escherichia Coli $\beta$ Propeller Protein YjhT." Journal of Biological Chemistry 283 (8): 4841-49. https://doi.org/10.1074/jbc.M707822200.

Sly, Laura M., Donald G. Guiney, and Neil E. Reiner. 2002. "Salmonella enterica Serovar Typhimurium Periplasmic Superoxide Dismutases SodCI and SodCII Are Required for Protection against the Phagocyte Oxidative Burst." Infection and Immunity $\quad 70 \quad$ (9): 5312-15.
https://doi.org/10.1128/IAI.70.9.53125315.2002.

Sydenham, Mark, Gillian Douce, Frances Bowe, Saddif Ahmed, Steve Chatfield, and Gordon Dougan. 2000. "Salmonella enterica Serovar Typhimurium SurA Mutants Are Attenuated and Effective Live Oral Vaccines" 68 (3): 1109-15.

Tamayo, Rita, Sara S Ryan, Andrea J Mccoy, and John S Gunn. 2002. "Identification and Genetic Characterization of PmrARegulated Genes and Genes Involved in Polymyxin B Resistance in Salmonella enterica Serovar Typhimurium" 70 (12): 6770-78. https://doi.org/10.1128/IAI.70.12.6770.

Uzzau, Sergio, Lionello Bossi, and Nara Figueroa-bossi. 2002. "Differential Accumulation of Salmonella [ $\mathrm{Cu}, \mathrm{Zn}$ ] Superoxide Dismutases SodCI and SodCII in Intracellular Bacteria: Correlation with Their Relative Contribution to Pathogenicity" 46: 147-56.

Wang, Y, B M Spratling, D R Zobell, R D Wiedmeier, and T A Mcallister. 2018. "Effect of Alkali Pretreatment of Wheat Straw on the Efficacy of Exogenous Fibrolytic Enzymes 1," no. July: 198-208.

Zeiner, Sarah A, Brett E Dwyer, and Steven Clegg. 2012. "FimA, FimF, and FimH Are Necessary for Assembly of Type 1 Fimbriae on Salmonella enterica Serovar Typhimurium" 80 (9): 3289-96. https://doi.org/10.1128/IAI.00331-12.

\section{How to cite this article:}

Arijit Shome, Manoj Kumawat, Pavan Kumar Pesingi, Sanjeev Kumar Bhure and Manish Mahawar. 2020. Isolation and Identification of Periplasmic Proteins in Salmonella Typhimurium. Int.J.Curr.Microbiol.App.Sci. 9(06): 1923-1936. doi: https://doi.org/10.20546/ijcmas.2020.906.238 